\title{
Rubén Darío en el debate sobre la literatura nacional nicaragüense
}

\section{Rubén Darío in the Debate on Nicaraguan National Literature}

\author{
Diana Moro \\ Universidad Nacional de la Pampa \\ Facultad de Ciencias Humanas \\ Instituto de Investigaciones Lingüísticas y Discursivas, Argentina \\ diana.morog@gmail.com
}

\section{Resumen}

El debate sobre la literatura en Nicaragua, en diversos periodos de la historia del país, se organiza a partir de la figura, la estética y la obra de Rubén Darío. No sólo el nacimiento y muerte del poeta en suelo vernáculo constituyen aspectos centrales en la apropiación realizada, sino, sobre todo, el capital cultural internacional construido a través de su vida errante y del cosmopolitismo en su obra. La apropiación de su estética, así como los distanciamientos y los debates sobre su aporte perviven en diferentes momentos de la historia literaria nicaragüense. Exploraremos algunas intervenciones de intelectuales integrantes del Grupo Nicaragüense de Vanguardia, en especial, su revisión crítica posterior y el aporte que significó la revista Ventana en la década de 1960. Finalmente, se observará que durante la época revolucionaria, 1979-1989, la figura de Darío concentra, por lo menos, dos apropiaciones simultáneas, la "antiimperialista" y la "mestiza". Todas las perspectivas coinciden en la convicción de que, en Nicaragua, no habría literatura sin el magisterio de Darío.

\section{Palabras Clave}

Rubén Darío, Nicaragua, literatura nacional, Movimiento Nicaragüense de Vanguardia, revista Ventana.

\section{Abstract}

The debate on literature in Nicaragua, at various moments in the country's history, is elaborated on the figure, aesthetics, and work of Rubén Darío. Not only the birth and death of the poet on vernacular soil are central aspects in the appropriation made, but above all, the international cultural capital built through his wandering life and cosmopolitanism in his work. The appropriation of his aesthetics, as well as the distancing and debates about his contribution, persist in various moments of 


\section{Diana Moro}

Nicaraguan literary history. We will explore some interventions by Nicaraguan intellectuals who are members of the Avant-garde Group, above all, their subsequent critical review and the contribution that Ventana magazine made in the 1960s. Finally, it will be observed that during the revolutionary decade, 1979-1989, the figure of Darío concentrates, at least, two simultaneous appropriations, the "anti-imperialist" and the "half-blood". Both perspectives coincide in the conviction that, in Nicaragua, there would be no literature without the magisterium of Darío.

\section{KEYWORDS}

Rubén Darío, Nicaragua, national literature, Avant-garde Nicaraguan Group, Ventana magazine.

RECEPCIÓN: 28/06/2020

ACEPTACIÓN: 03/09/2020

No se puede negar que la historia de Nicaragua, como la de todo país americano y hasta posiblemente más que la de casi todos ellos, ha estado siempre abierta a lo universal. fosé Coronel Urtecho (1966)

La literatura nicaragüense comienza [...] como traducción Pablo Antonio Cuadra [1981] (1997)

El trabajo crítico se puede hoy concebir como una libre instrumentación definida por su capacidad dialógica. Fulio Ortega (2003)

El alcance nómada y trashumante de la subjetividad dariana, pese a su propia internalización de esta modernidad, sutura mundos que seguimos sin consolidar. Julia Medina (2018)

\section{Introducción}

Ci bien el auge de los estudios trasatlánticos, acaecido en los últimos años, se ha comprendido como consecuencia de realineamientos geopolíticos globales y también como nuevo avance de un "remozado Hispanismo" (Trigo, 2012: 19), aquí interesa la apertura hacia nuevos diálogos probables, posibles articulaciones que complejicen las formas de entender las literaturas nacionales o los movimientos culturales de una región. En este sentido, Julio Ortega señalaba en 2015: "los estudios transatlánticos se definen mejor por su carácter inclusivo, metodología dialógica y voluntad anticanónica; esto es, por su despliegue procesal" (Ortega, 2015: 41); y agregaba: "la 
metáfora 'transatlántica' es el diseño de conjuntos en contacto, que cotejan, debaten y serializan su combinatoria tanto como postulan horizontes de futuro, que ofrecen a lo local espacios virtuales de respiración y proyección” (Ortega, 2015: 42-43).

Otro aporte que posibilita una búsqueda de articulaciones no etnocéntricas es la noción de polisistemas elaborada por el crítico israelí Itamar Even-Zohar, que enfatiza "la multiplicidad de intersecciones" (Even-Zohar, 1990: 4) entre distintos sistemas y estratos (sociales, culturales, lingüísticos). En relación con esa teoría, aparece la noción de repertorio: determinados repertorios canonizados ceden y dan lugar a otros repertorios, según el ejemplo señalado por Even-Zohar.

En este artículo, nos proponemos indagar el lugar de la figura, la obra y la estética dariana en el sistema literario nacional nicaragüense. La idea de polisistemas mencionada como marco teórico permite partir de la premisa de que, en Nicaragua, el sistema literario nacional es uno hegemónico, pero que existen otros con particularidades lingüísticas específicas y tradiciones culturales diferentes. ${ }^{1}$ Aun en el contexto de la literatura nacional oficial, es posible valorar cómo, según la perspectiva desde la cual se haya abordado la obra de Rubén Darío, se ha enfatizado uno u otro repertorio de su vasta obra. ${ }^{2}$

En un estudio anterior, habíamos apuntado que tanto las circunstancias del nacimiento y muerte de Darío en suelo nicaragüense como la errancia y, por ende, el conocimiento y el prestigio que supo ganarse en círculos literarios diversos de América y de Europa, pero también en esferas políticas, por ejemplo, de Chile y de Buenos Aires, constituyen, todo esto en conjunto, un capital cultural que los sectores que detentaron el poder en Nicaragua (el somocismo y el sandinismo) asumieron como anclaje cultural de su propia política. En ese marco, sostenemos que la figura y la obra de Rubén Darío, aunado al modernismo en tanto estética de fin de siglo que define, en gran medida, el ingreso a la modernidad de la literatura en América Latina, organizan el debate sobre la constitución del sistema literario nicaragüense. ${ }^{3}$ Nos detendremos en describir algunos momentos clave de ese debate y, en su recorrido, veremos la presencia del cisne como símbolo antiburgués, el carácter mestizo ("la pluma debajo del sombrero", al decir de Unamuno) y la enemistad con "los búfalos de dientes de plata". Esos repertorios se mantienen durante todo el siglo xx y aún persisten como sustento de la literatura nacional. No obstante, el magisterio de Darío en relación con la producción vernácula no estuvo exento de polémica. El primer conato de rebeldía

${ }^{1} \mathrm{Al}$ respecto, véase Gianni (2007).

${ }^{2}$ El gobierno de la familia Somoza realizó una apropiación interesada de la figura y la obra de Darío. Véase Moro (2017).

${ }^{3}$ Sergio Ramírez, en el ensayo "Volcanes y Balcanes", en la década de 1970, como también luego, durante el periodo revolucionario, reivindicó la figura de Darío en la constitución de la literatura de su país. 


\title{
Diana Moro
}

fue protagonizado por el Movimiento Nicaragüense de Vanguardia, contemporáneo de todo el fenómeno continental y europeo de ruptura, hegemónico en la poesía de principios del siglo $\mathrm{xx}$.

\section{Los vanguardistas incorporan a Rubén Darío en el canon nacional}

Como se sabe, la emergencia del Movimiento Nicaragüense de Vanguardia se asocia a la presentación en sociedad de la "Oda a Rubén Darío" de José Coronel Urtecho en 1927, que fue asumida como un manifiesto por el grupo. Otros poemas escritos por integrantes de ese colectivo incluyeron referencias a Darío: la serie denominada "Los cisnes" de Octavio Rocha, "Sonsoneto n 2 - Leda, de Herrera" de Pablo Antonio Cuadra y "Preludio a Managua en B Flat" de José Román. ${ }^{4}$ Estos poemas se hacen eco del repertorio dariano. Por un lado, retoman el motivo del cisne como contraposición al burgués y como símbolo del distanciamiento con el romanticismo; por otro, recuperan la tensión entre el "coloso del norte" con su idioma inglés y el mundo latino, hispano. Así, Octavio Rocha caracterizaba el "cisne burgués" como "Bajo y obeso/ obeso y bajo" (Solís, 2001: 181). En otro poema titulado: "El cisne romántico", hay un distanciamiento del romanticismo: "Usa una rosa en el pico/ y se pinta las ojeras" (Solís, 2001: 181); y, en el poema "El cisne poeta", leemos: "Vive en la fuente/ de agua inquieta/ el cisne poeta;/ y ama a Rubén" (Solís, 2001: 181). En el "Sonsoneto n 2 - Leda, de Herrera" de Pablo Antonio Cuadra, aparece también el ataque al burgués en sintonía con el planteo dariano:

\author{
"Si transformar pudiese mi figura" \\ como Júpiter fácilmente hacía \\ no del dariano cisne tomaría \\ su blanca interrogante arquitectura; \\ de un obeso burgués la envergadura \\ idealizado en cerdo fingiría [...] \\ Por eso en metamorfosis burguesa \\ convierto en cheque este soneto airado \\ y pongo precio a su mayor tesoro (Solís, 2001: 183). ${ }^{5}$
}

\footnotetext{
${ }^{4}$ Los textos mencionados fueron publicados en los números 22/23 de la revista El Pez y la Serpiente, volumen especial de autohomenaje realizado por José Coronel Urtecho y Pablo Antonio Cuadra en 1978/79, a cincuenta años del accionar del movimiento. También aparecen en la compilación realizada por Pedro Xavier Solís, El movimiento de vanguardia en Nicaragua. Análisis y antología (2001). Las citas corresponden a esta última publicación.

${ }^{5}$ El poeta recurre al poema de Fernando de Herrera como intertexto explícito - el primero y el último verso - y recupera el gesto de la poesía satírica, propia del barroco español, al transformar un soneto de amor desproporcionado en una sátira social. El soneto original:
} 
"Preludio a Managua en B Flat", de José Román, es un poema cuyo tópico refiere a la intervención estadounidense en Nicaragua; incluye el verso de Darío tantas veces citado en los años posteriores: "Cuántos millones de almas hablaremos inglés" (Solís, 2001: 196).

Contra "la mala poesía" se entablaba la disputa explícita del grupo granadino en este periodo. Esa conclusión puede sostenerse a partir de la lectura de uno de los textos escritos en Vanguardia, la página fundada en 1931 en el diario El Correo de la ciudad de Granada:

Aquí no hay materia ni doctrina que discutir, sino que tenemos que inventar materia y doctrina. No reformar, sino formar. Si hacemos versos malos, los hacemos malos ex profeso. Quisiéramos hacerlos más malos aún, genialmente malos, para que todo el mundo se dé cuenta de que son malos, y así comiencen a saber lo que es un mal verso y, por contraste, lo que es un verso bueno, que es lo que nunca se ha sabido en Nicaragua. A nosotros se nos hizo aprender de memoria kilómetros de malos versos como ejemplo y modelo de buenos. Se nos dio gato por liebre, y hoy se ofenden nuestros profesores porque les devolvemos gato por gato (Cuadra citado en Cardenal, 1987: 9).

Podríamos suponer que, en esos kilómetros de versos, estarían los epígonos de la estética dariana. Pablo Antonio Cuadra (1912-2002), en su discurso de ingreso a la Academia Nicaragüense de la Lengua como miembro de número, recordaba el distanciamiento de su grupo con Darío:

Yo mismo cuando comencé en mi patria - con otros jóvenes poetas nicaragüenses el movimiento lírico de revolución y reacción anti-modernista - disparé irreverencias contra el amado enemigo (así le decíamos), porque no encontraba al hombre, al nicaragüense, al hispano americano en su espesa colección de disfraces. [...] Lo atacamos — parodiando a Heine - de ser un zenzontle nicaragüense que hacía su nido en la barba de Víctor Hugo (Cuadra, 2004: 115).

En ese texto que data de 1944, cuando su autor tenía 32 años y hacía escasos diez que había fundado la Antiacademia como acción vanguardista, Cuadra recuperaba la figura de Darío para Nicaragua, precisamente con motivo de su ingreso en la Academia Nicaragüense de la Lengua. Esa presentación formal se titula "Introducción al pensamiento vivo de Rubén Darío"; podríamos decir que es el primer gesto de incor-

\footnotetext{
"Si transformar pudiese mi figura/ como el Ideo Júpiter solía,/ en blanco cisne vuelto ya sería,/ mirando de mi Leda la luz pura, / y sin algún temor de muerte oscura/ en honra suya el canto ensalzaría,/ su frente y bellos ojos tocaría, ensandeciendo, ufano, en tal ventura.// Mas en luciente pluvia convertido/ perdería el electro la fineza,/ si el velo esparce, suelto en rayos de oro;// pero siendo en la falda recogido,/ y junto al esplendor de la belleza,/ tendría el precio del mayor tesoro" (Fernández, 1786: 46).
} 


\section{Diana Moro}

poración, de parte de un referente vanguardista, de Rubén Darío al canon literario nicaragüense. Resulta interesante la operación de recuperación que realizaba Cuadra de Darío, porque podría constituirse en un precursor de la mirada trasatlántica. Declara que Nicaragua se encuentra en un punto geopolítico "umbilical": "Nicaragua surge a la historia como tierra umbilical, como centro de cruce y tránsito de rutas geográficas e influencias culturales" (Cuadra, 2004: 121). Repasa la historia de Nicaragua, y concluye: "debemos fijar nuestra atención en esa insistente tendencia de los sucesos nicaragüenses a desbordar lo nacional y a producirse, cualquiera que sea su orientación e ideología, dentro de una categoría que podemos llamar, en lengua rubeniana: imperial" (Cuadra, 2004: 125).

Así, expone la tesis de la importancia del espacio interoceánico para los intereses imperiales de España e Inglaterra, primero, y de Estados Unidos, después. En esa tierra de intersecciones político-culturales y de tránsito, Rubén Darío se constituye como un símbolo cosmopolita. Dice Cuadra: "Nosotros pretendíamos que Rubén viniera líricamente a Nicaragua, cuando precisamente en ese irse, en ese desbordar su nacionalismo, manifestaba su nicaraguanidad. Es mucho más nicaragüense Rubén en 'Divagación' o en 'Salutación del Optimista' que en 'Intermezzo Tropical'” (Cuadra, 2004: 129).

También José Coronel Urtecho recuperaba al "amado enemigo". En un texto de 1966, titulado "Introducción al tema de la universalidad nicaragüense", señala: "Nacionalidad, hispanidad, latinidad, occidentalidad [...] para nosotros sólo designan distintos grados de unidad en la universalidad" (Coronel, 1966: 4). Argumenta que esas condiciones integran el ser nicaragüense y, en relación con Rubén Darío, apunta:

La más alta manifestación de la universalidad nicaragüense es, por supuesto, Rubén Darío. Él es el paradigma de nuestra universalidad en su más pura forma. El hecho sobrepasa, desde luego, los límites nacionales de lo nicaragüense - porque Rubén no es sólo un gran poeta de Nicaragua, sino, además, de cualquier otro de los países de lengua española, empezando por España - pero, precisamente, es esto lo que le da su carácter de símbolo de la universalidad nicaragüense (Coronel, 1966: 6).

No hace falta, seguramente, aclarar que el término "universalidad" es sinónimo de "occidental". Coronel Urtecho expresa: "Es con Rubén y por Rubén que la poesía de Nicaragua adquiere a un mismo tiempo conciencia de sí misma y de su propia universalidad" (Coronel, 1966: 6). Y más adelante, dice: "la poesía es hasta ahora el único producto nicaragüense de indiscutible valor universal” (Coronel, 1966: 7). A través de esa línea argumental, ubicaba a Darío en el centro del canon de la literatura nacional nicaragüense. 
Este mismo autor, en un texto de 1962, caracterizaba a Nicaragua como "mestiza":

No es necesario consultar las estadísticas [...] para saber que Nicaragua figura entre los países latinoamericanos donde ha existido un más completo mestizaje, español, indio y negro [...] En Rubén se produjo una armonía superior, un feliz equilibrio del mestizaje nicaragüense gracias, en buena parte, a la no menos inclusión universalista de su temperamento (Coronel: 1962: 279-280).

Resulta evidente que el reconocimiento de Darío por su ubicación en el mundo occidental europeo y en la configuración de una literatura en lengua castellana habla de los valores sustentados en el campo intelectual nicaragüense, cimentado en la confianza en que la escritura constituye la base de la modernidad. ${ }^{6}$ En ello se sostiene, sin duda, la necesidad de dotar a Nicaragua de una literatura, y, en ese sentido, el valor de Darío es indiscutible en aquel momento y en los años sucesivos.

Por su parte, Pablo Antonio Cuadra escribirá otros textos referentes a Darío, incluidos en el volumen El nicaragüense, publicado originalmente en 1967. ${ }^{7}$ De ese libro destacamos "La dualidad de Rubén" y "Un nicaragüense llamado Rubén Darío". ${ }^{8}$ En este último texto, expone el modo en el que los vanguardistas reconocen a Darío como el poeta nicaragüense, a través de un discurso autocrítico, y toma como un valor la errancia del poeta, que lo ubica en la "universalidad":

El ataque, o mejor dicho la extrañeza nuestra ante la obra de Rubén fue el fruto de una visión superficial y apasionada en un momento revolucionario: nuestra literatura trataba de afirmar su nacionalidad (ieran los años de Sandino!) — comenzaba a nacer una literatura nacional - y nosotros exigíamos a Rubén el tema nacional sin percatarnos de que nuestra vuelta a la tierra y al hombre de nuestra tierra sólo era posible gracias al regreso de ese Ulises cuyo canto errante nos había recuperado las dimensiones universales de lo nacional.

Sin él no hubiéramos encontrado lo nacional sino lo provinciano y folklórico: no hubiéramos descubierto sino que nos hubiéramos sumergido en la caverna y el dialecto (Cuadra, 1987b: 73).

Y le confiere a Darío el lugar del fundador. Menciona el poema "Allá lejos", y afirma: "Al pie de este poema, creo yo, nace la literatura nicaragüense" (Cuadra, 1987b: 75). En "Rubén y la dualidad" inicia su ensayo con la transcripción del poema "En las constelaciones”, fechado en abril de 1908 "en el Océano Atlántico" (Darío,

\footnotetext{
${ }^{6}$ Erik Blandón opone la "nación escrituraria forjada por la élite orgullosa de hablar una lengua europea" a la cultura oral indígena. Señala que estas comunidades no cabían en ese concepto de nacionalidad (Blandón, 2011: 176).

${ }^{7}$ La edición que citamos corresponde a la de 1987.

${ }^{8}$ En 1959, Cuadra recibe el Premio Centroamericano Rubén Darío de Poesía y, en 1964, el Premio Rubén Darío de Poesía Hispánica.
} 
1977: 449). Y, a continuación, apunta: "es para mí uno de los más dramáticos testimonios de su nacionalidad [...] Porque Rubén es la expresión — el verbo- de la dualidad nicaragüense" (Cuadra, 1987a: 17).

Más tarde, en el texto "La revolución hispanoamericana de Darío", escrito en la década de 1970 y recuperado recientemente, le adjudica a la obra dariana la tercera independencia de Nicaragua, precisamente por su carácter cosmopolita. Comienza de la siguiente manera:

Rubén Darío, visto desde su tierra nicaragüense, es el inaugurador de la literatura nacional y el que le dio verbo a la nacionalidad nicaragüense. Antes de Darío, nuestra nacionalidad era infante (infante significa "que todavía no habla"): hablaban las tribus, hablaban los localismos, los partidos, los vecindarios y con frecuencia la barbarie. Fue su verbo el que sacó a Nicaragua de los provincianismos en que "la latina estirpe" se había sumergido. Después de Darío - aunque la política levante una y otra vez los muros de la parcialidad - su obra mantiene encendida la vocación universalista como componente radical de nuestra nacionalidad (Cuadra, 2016: 281).

Allí, con mayor claridad, se opone la oralidad a la escritura (literatura) y se identifican esos términos con barbarie y civilización o modernidad, respectivamente.

En el texto ya mencionado, "Un nicaragüense llamado Rubén Darío", publicado en 1967, Cuadra expresaba la existencia del debate acerca de la figura de Rubén Darío: "nuestra injusticia, que creíamos borrada, trata de renacer en ciertos sectores actuales agudizada por una política que inocula un sentimiento acomplejado y rencoroso de la nacionalidad" (Cuadra, 1987b: 73). Podríamos conjeturar que uno de esos debates, si acaso hayan existido otros, podría ser el que había tenido lugar, unos años antes, en las páginas de la revista Ventana.

\section{Los "jóvenes" del sesenta y la revista Ventana}

Ventana fue una revista universitaria que se editó en León, Nicaragua. Dirigida por Sergio Ramírez y Fernando Gordillo, recibió el auspicio del rector de la Universidad Nacional Autónoma de Nicaragua (con sede en León) en aquellos años, Mariano Fiallos Gil, mentor de los jóvenes. ${ }^{9}$ Entre abril de 1960 y diciembre de 1963, se publicaron diecinueve números ${ }^{10}$ y fue contemporánea de la revista El Pez y la Serpiente, que Pablo Antonio Cuadra fundó en 1961; su primer número apareció en febrero de ese año. Una diferencia primordial entre ambas es que el carácter de revista universitaria

\footnotetext{
${ }^{9}$ Sergio Ramírez y Fernando Gordillo eran los referentes del denominado Frente Ventana, una agrupación político-cultural con sede en León y en el contexto universitario.

${ }^{10}$ En 1990, Sergio Ramírez publicó una edición facsimilar de la revista.
} 
de la primera explica su existencia acotada. ${ }^{11}$ El Pez y la Serpiente se definía como una revista cultural, y su permanencia ocupó prácticamente toda la segunda mitad del siglo xx, hasta el año 2003, un tiempo después de la muerte de su director. No hay intención aquí de realizar comparaciones entre ambas revistas, sino de establecer las coordenadas temporales y epocales en que fueron proyectadas, ${ }^{12}$ ya que tanto Pablo Antonio Cuadra como los integrantes del Frente Ventana manifestaron la preocupación por la configuración de una literatura nacional nicaragüense, y la figura de Rubén Darío resulta central en ese debate.

Ventana se presenta como una caja de resonancia de las inquietudes literarias de esos jóvenes de principios de la década de $1960,{ }^{13}$ y es evidente, luego de una lectura atenta del conjunto de números publicados, que una de las preocupaciones centrales de sus editores, militantes estudiantiles, y de los jóvenes intelectuales que colaboraban en ella era la cuestión nacional en el contexto de la lucha contra la dictadura de Somoza. Pensaban en una literatura que expresara el compromiso social, y, aun así, una de las características de la revista es la profusa presencia de traducciones. ${ }^{14}$ Ello habla

${ }^{11}$ El último número de Ventana anuncia su final: "Ventana, una revista de literatura experimental [...] desaparece ahora para dar paso a una nueva publicación que resultará de la fusión con Cuadernos universitarios" (Ventana, número 19, 1963: 1).

${ }^{12}$ Un estudio sobre los primeros quince números de la revista es "El discurso cultural en la revista El Pez y la Serpiente en sus primeros quince años (1961-1976)" de Gloriantonia Henríquez. Allí, la autora señala que se interrumpió la publicación de la revista durante seis años, entre 1983 y 1989 (véase Henríquez, 1992).

${ }^{13}$ José Coronel Urtecho señala sobre el Frente Ventana: "Ventana rompe con lo anterior, pero no es una total ruptura idiomática o literaria en sí, porque ya se habían hecho avances que no se podían abandonar. Existían elementos creados por el Movimiento de Vanguardia que les permitían a estos jóvenes la libertad verbal, la proximidad a nuestra lengua nicaragüense" (Coronel, 1987: 12).

${ }^{14}$ La siguiente lista corresponde a las traducciones en Ventana, ordenadas por número. Núm. 1: poema de Salvatore Quasimodo, premio Nobel 1959, "Hombre de mi tiempo", traducción al castellano de Fernando Quiñones (8). Núm. 4: "El hombre que fue Ghesterton" por Napoleón Chow (4-5). "Grandes poetas italianos de nuestro tiempo" (8): Victorio Bodini, Giorgio Soaví, Pier Paolo Passolini, Romeo Luchese, Bruno Conti y Bartolo Cataffi, selección y versión castellana de Fernando Quiñones. Núm. 6: nota de Mario Maurin sobre Saint-John Perse, poeta francés (nacido en Las Antillas), premio Nobel 1960 (6 y 8). "Imágenes para Crusoe" de Saint-John Perse, versión de Jorge Zalamea, traductor de la obra del autor (7). Núm. 8: "Carta a un joven poeta" de Rainer Maria Rilke (6). Núm. 9: "El interior de la bolsa" de Tennesse Williams, traducido por Roberto Cuadra (2). Nota breve sobre Herman Kasack, poeta alemán (7). En las páginas centrales: una "breve selección de poesías chinas, vertidas del francés al español por Álvaro Yunque, y que pertenecen a la colección 'Poetas chinos"” (8-9). "Albada Harlem" de Thomas Merton, traducido por Ernesto Cardenal (13). "Solo en el sueño" de Richard Eberhart, traducido por Roberto Cuadra (14). Núm. 10: poemas de Langston Hughes y una breve reseña de su vida y labor literaria (1). En las páginas centrales: 
de la búsqueda de lo nacional en vinculación con lo internacional o cosmopolita. A partir de la noción de "polisistema" y del aporte de María Teresa Gramuglio referido a la posibilidad de pensar las literaturas nacionales como el resultado de cruces diversos de tradiciones varias que no necesariamente se ciñen a las fronteras territoriales, ni del país ni de la región — según señalábamos en un trabajo anterior-, es posible pensar en ese modo de configurar y de construir lo nacional sobre la base de una red de vínculos o repercusiones internacionales. ${ }^{15}$

Así, sobre la edificación de una literatura nacional, por ejemplo, aunque la mayoría de los números de Ventana expresan la búsqueda a través de las traducciones, el último, el 19, muestra un repertorio constitutivo de la literatura nacional nicaragüense al destinar toda la revista a la publicación de sonetos escritos por autores del país. ${ }^{16}$

una selección de poemas otomíes, guaraníes, quechuas y náhuatl (8-9). Núm. 11: "La poesía beats de Norteamérica", se publican tres poesías: una de Allen Ginsberg, otra de Philip Lamantia y la tercera de John Ashbery, traducidas al español. En la misma página, un poema de Ernesto Cardenal (4). "Centinela de fuego" de Thomas Merton, traducido por Napoleón Chow (5). Núm. 12: "Un cuento de la dinastía Tang. 'El mortero de jade y el majador", traducido por Napoleón Chow (5-8). "Canciones de amor de tribus norteamericanas", traducción de Roberto Cuadra (27-28). "Poesía griega. Constantino Cavafy", una reseña de ubicación del autor y varios poemas traducidos por Roberto Cuadra (29-32). "La tierra del salvaje" de Jack Micheline, traducción de Roberto Cuadra (35-36). Núm. 13: entrevista a William Faulkner, realizada en 1958 y publicada por primera vez en la revista brasileña Coluna. Homenaje por su muerte, junio de 1962, vertida del portugués por F. G. [Fernando Gordillo] (1-8). Núm. 14: se inicia con el largo poema "Aullido" de Allen Ginsberg, traducido por Roberto Cuadra (1-13); se menciona al final que el poema había sufrido censura por considerarlo "lascivo y obsceno" (13). "Jóvenes airados en Nicaragua" de Stefan Baciu, traducción de Sergio Ramírez (36-37) y "Una carta de Stefan Baciu, escritor brasileño" (38). Núm. 15: "Epigramas" de Ezra Pound, traducidos por José Coronel Urtecho (21-22). "Norteamérica y sus poetas", una selección de poesías de poetas norteamericanos: Robinson Jeffers, Hart Crane, Bartolomeo Vanzetti, William Carlos Williams y Archibald MacLeish, traducidos por José Coronel Urtecho y Ernesto Cardenal (30-36). Núm. 16: "Poetas de Rusia. Evgene Evtuchenko", se incluye lo siguiente: "Las formidables traducciones son del joven pintor nicaragüense Alejandro Aróstegui" (33), se publican 3 poemas (33-38). Núm. 18: "La última soledad de Ezra Pound", nota y reportaje realizados por Grazia Livi, desde Venecia, Italia, cuando el poeta tenía 70 años (20-25). "Traducciones de poesía china. Lí Po", se presentan seis poesías, con la siguiente mención: "Traducción directa del chino por Camilo Vigil (nicaragüense)" en un recuadro al pie (26-28). Se publica un poema del norteamericano Robert Frost, recientemente fallecido; el poema se titula "A Patch of Old Snow", traducido al español por Mariano Fiallos Oyanguren, profesor de filosofia en la Universidad Nacional (36-37). "Poetas de Francia. Jacques Prevert", se publica el poema "Linterna mágica de Picasso", en traducción de Michele Najlis (38-42).

${ }^{15}$ Véase Moro (2019).

${ }^{16}$ En la antología de sonetos nicaragüenses, se incluyen poetas de todos los tiempos, por orden cronológico. Empieza con Ramón Mayorga Rivas, nacido en 1862, continúa con Rubén Darío, de 1867, y culmina con Fernando Gordillo, uno de los jóvenes directores de la 
Al final de este volumen, en "Notas sobre la antología de sonetos nicaragüenses", se menciona que el soneto es una forma poética que se encuentra en los "albores de la literatura española [...] También en otras lenguas, el soneto estuvo en las mismas fuentes de la lengua". Y se aclara: "en el criterio de los encargados de la selección privó el ánimo de poner por encima aquellos poemas en que se tocara lo vernáculo nicaragüense pero sin dejar por fuera de ninguna manera a aquellos que alcanzan un alto grado para figurar de por sí” (Ventana, núm. 19, 1963: 40).

En ese contexto de búsqueda y de exploración de diversas estéticas y lenguajes, se presenta una especie de polémica acerca de la validez o de la actualidad de Rubén Darío en esa coyuntura literaria. En el número 2 (julio de 1960) aparece una nota sin firma, que ocupa el lugar del editorial, titulada "Darío, el manoseado y la verdadera dirección de la poesía", y en el número 5 (octubre de 1960) se incluye otra, firmada por Raúl Elvir Rivera, "Vigencia de Rubén Darío". Esos artículos pueden leerse como una cuasi-polémica, dado que explícitamente el autor del segundo, un poeta que había comenzado a escribir en la década de 1940, responde a los jóvenes de Ventana, responsables del primero de los dos artículos, quienes en la nota inicial afirman: "Esta juventud nicaragüense es la que debe mirarle como un héroe y no como un maestro: como un altar y no como un faro" (Ventana, núm. 2, 1960: 1). El segundo artículo expresa el ánimo polémico respecto de "algunos comentarios aparecidos sobre nuestro poeta en un ejemplar anterior de esta misma Revista" (Ventana, núm. 5, 1960: 1), y sostiene, luego de desarrollar varios argumentos, que Darío no "ha de perder su actualidad [...] hay mucho que estudiar y descubrir en él” (Ventana, núm. 5, 1960: 2).

Resulta de interés el planteamiento de la primera de las notas porque, en cierto sentido, sus autores asumen una postura similar a la que habían tomado los poetas del Movimiento Nicaragüense de Vanguardia durante los años veinte, aunque rápidamente se corren de ese posicionamiento. En la aludida nota del número 2 de Ventana, sus editores expresan:

Darío, el Rubén de nosotros, arrastró consigo toda una época: nada menos que soltó del poema las amarras de la medida. Y nació con él la esplendorosa era modernista. Pero para desgracia de la juventud nicaragüense, Rubén Darío ha trascendido demasiado entre nosotros, y a tantos años de que su gloria fue declarada inviolable, aún muchos creen que su huella es fresca y propicia para asentarle un nuevo pie encima (Ventana, núm. 2, 1960: 1).

Como puede leerse en la cita, convocan a dejar de lado la herencia dariana. Tres meses después, en el número 5, se publica una réplica a esa nota firmada por el inge-

revista, nacido en 1940, pasando por más de veinte poetas nacidos entre la segunda mitad del siglo XIX y la primera del xx. 
niero (graduado en 1954), poeta y traductor Raúl Elvir Rivera (1927-1998), colaborador de Ventana. El autor señala que tanto la aparición de nueva bibliografia rubeniana como los comentarios en un número anterior constituyen el punto de partida para la escritura del artículo sobre la actualidad de Rubén Darío. Su argumentación se centra, por un lado, en la visibilidad de Nicaragua en el mundo a través de Darío; para ello, toma una cita de Juan Ramón Jiménez: "Si cualquier catástrofe geológica hiciera desaparecer a Nicaragua [...] bastaría el Poema de Otoño de Rubén Darío, para que Nicaragua siguiera incorporada al mundo" (Ventana, núm. 5, 1960: 2). Y, por otro, en la figura de Darío "como elemento de nuestra nacionalidad" no sólo nicaragüense, sino hispanoamericana: "porque en él se descubre una sensibilidad nueva cuya originalidad está en asimilar y fusionar diferentes elementos culturales del acervo mundial para entregarnos luego con voz inconfundible y propia, una creación en que lo americano puso su sello vital" (Ventana, núm. 5, 1960: 2). Ambos argumentos se enmarcan en un pensamiento que hoy denominamos trasatlántico, y, lo que es más importante, esa línea de rescate de Darío constituía la base de la búsqueda de Ventana y del grupo que la sostenía. En el último párrafo, Elvir Rivera dice: "a medida que lo leemos y lo vamos conociendo, se van haciendo más claros nuestros propios contornos" (Ventana, núm. 5, 1960: 2).

Sin lugar a dudas, en esa cuasi-polémica, esta última postura es la que sale victoriosa, ya que en dos números posteriores se le rinde homenaje en el aniversario de su muerte: en el número 12 (abril de 1962) y en el 16 (enero-marzo de 1963). En el primero de estos números se publica el poema "La canción del oro" completo; en la primera página de la revista aparece una foto inédita de Rubén Darío, y, más adelante, un artículo de Juan Aburto, "Actual vivencia humana de Rubén Darío". El autor de este texto aborda el recuerdo de ciertos nicaragüenses que, en ese momento, manifiestan acerca de Rubén Darío: "el recuerdo de su voz recitando versos", "la manera de caminar". Y señala: "Para muchas gentes del pueblo nicaragüense, Darío es el 'mejor poeta de Nicaragua, tal vez hasta de Centro América o del Mundo', y un individuo, además, que gusta mucho de beber" (Ventana, núm. 12, 1962: 25). Culmina su artículo con una aseveración: "quedará extinta la postrera vivencia terrenal de Darío. Entonces Rubén habrá penetrado definitivamente a morar en el Olimpo" (Ventana, núm. 12, 1962: 25). Es interesante este tipo de abordaje porque, primero, se lo humaniza y, luego, se aspira a la sacralización. Esa construcción de Darío como monumento nacional corresponde a la realizada por el régimen somocista, por tal motivo llama la atención que también aparezca en Ventana, colectivo de férreos opositores. Es evidente que no se podía escapar de la elaboración monumentalizada de la figura de Darío. ${ }^{17}$

${ }^{17}$ Cabe recordar que, en el mismo momento de la muerte de Darío, los sectores de poder en Nicaragua proceden a una monumentalización de sus restos; más tarde, en la década de 1940, el gobierno del primer Somoza, con el consenso de los grupos conservadores, de la 
El número 16 comienza del mismo modo, es decir, con la pretensión de homenaje: "Ventana. 47 aniversario de la muerte de Rubén Darío". Se incluye la primera y la última hoja del manuscrito de "Canción de otoño en primavera" (primera versión, conservada en el Seminario Archivo "Rubén Darío" de Madrid). Se transcriben los versos y se publica el facsímil del manuscrito. ${ }^{18}$ Además, en la misma revista, aparece un poema de Alfonso Cortés, titulado "Poema del monumento a Rubén Darío" y escrito en el Hospital de Enfermos Mentales de Managua en febrero de 1963, así como un artículo referido al poeta, firmado por Sergio Ramírez, "Rubén Darío, la señal trascendente". Dicho texto es el primero de este último autor sobre Darío. ${ }^{19}$ Ramírez, también como sus antecesores, celebra la errancia: "un capítulo de la historia de Nicaragua se abre cuando un muchacho es anotado en un rol de barco que va de Corinto a Valparaíso" (Ventana, núm. 16, 1963: 5). Más adelante, asegura que no habría literatura en Nicaragua sin su magisterio:

Bajo este Rubén Darío la literatura de Nicaragua, grandemente respetada en España y América, dio a Alfonso Cortés, Azarías Pallais, Salomón de la Selva. Y toda la generación de vanguardia viene de su marca y los que siguieron a vanguardia le llevan, caudillo, por delante. Y ninguno de nosotros puede negarle. Él es la lengua de fuego donde se congrega la poesía (Ventana, núm. 16, 1963: 6).

Niega que la literatura de su país sea epígono de Darío: "Dueño del destino de la poesía nicaragüense, Rubén no habría de ser ni espejo ni fonógrafo" (Ventana, núm. 16, 1963: 6). Y concluye su argumentación con la idea de perpetuidad, es decir, Darío estará siempre presente en la literatura de Nicaragua:

Y por ese continuo otear de la literatura en el horizonte dariano; por ese continuo clavar de la pica en sus laderas; por esa insistencia de nuestra poesía sobre él, es que nosotros necesitamos a Rubén Darío cada vez más ancho, cada vez en nuevas dimensiones, cada vez lleno de nuevos fulgores y de nuevos matices pues le sabemos inagotable y perpetuo (Ventana, núm. 16, 1963: 7).

Sergio Ramírez volverá una y otra vez a recuperar la figura de Darío a lo largo de toda su trayectoria como escritor, tanto en la gestión de gobierno durante el periodo revolucionario (1979-1989) como después y hasta el presente.

Iglesia Católica y con el beneplácito de los círculos liberales, organiza una serie de actos conmemorativos y de homenaje con motivo del XXV aniversario de su muerte y ubican su figura como símbolo patrio, junto a la bandera nacional y en cercanía del caudillo (véase Ayerdis, 2005; Blandón, 2010; Moro, 2017).

${ }^{18}$ Se aclara, entre paréntesis al pie de página, que la copia de esos originales fue obsequiada a la Universidad y que se resguardaron en la casa en que vivió el poeta en León, la cual próximamente funcionará como Museo Archivo Rubén Darío, establecido así por ley nacional.

${ }^{19}$ El artículo está fechado, en León, febrero de 1963. 


\section{La apropiación revolucionaria}

La década de 1980 en Nicaragua fue pródiga en elaboraciones respecto de la literatura. En un marco de políticas de impulso a la cultura y a las artes, y con un discurso de refundación del país - luego de la destitución de la dictadura somocista-, la literatura como soporte nacional constituyó una de las principales preocupaciones culturales del Estado revolucionario. ${ }^{20}$ En ese contexto, la figura de Rubén Darío fue preponderante.

Han sido indagados, por ejemplo, los artículos aparecidos en la revista cubana Casa de las Américas, a cargo de intelectuales o cuadros políticos nicaragüenses, y ha sido analizada la presencia recurrente de Darío y de referencias a algunos tramos de su obra. ${ }^{21}$ Para componer una figura política de poeta nacional, se recuperan, entre otros, los textos darianos correspondientes al periodo de la España del "desastre", escritos a partir de 1898. ${ }^{22}$ Sergio Ramírez y otros testimonios aseguran que Carlos Fonseca se propuso rescatar a Rubén Darío para la causa popular y se ocupó de leer aquellos textos del poeta que no tenían circulación en la Nicaragua somocista. ${ }^{23} \mathrm{Al}$ respecto, Ramírez le dice a Arqueles Morales en una entrevista: "Transitando clandestino las calles de la esperanza, Carlos se pasaba los días en la Biblioteca Nacional recopilando textos de Rubén Darío y datos para sus propios textos revolucionarios" (Morales, 1985: 73). La operación discursiva de la intelectualidad revolucionaria consistió en la construcción de una galería de personalidades símbolos de la nación; las figuras centrales fueron Rubén Darío y Augusto César Sandino. Esa elaboración ya había sido desarrollada por Ramírez en su ensayo "Balcanes y volcanes" (1973) y se convirtió en un tópico común en el discurso revolucionario. Como ejemplo, podemos mencionar el discurso de Humberto Ortega, en el segundo congreso del Partido Comunista de Cuba; comienza de la siguiente manera:

${ }^{20}$ Sobre la organización estatal de la cultura, a través del Ministerio de Cultura gestionado por Ernesto Cardenal, y el papel de las distintas agrupaciones de artistas, puede consultarse Wellinga (1989 y 1994).

${ }^{21}$ Véase Moro (2015).

${ }^{22}$ Respecto de las imágenes de España que Darío compone en sus textos, de las cuales surge la calificación de "España del desastre", puede consultarse el artículo de Schmigalle (2003).

${ }^{23}$ Entre otros, podemos mencionar el testimonio de Omar Cabezas: "Carlos Fonseca era un gran admirador de Darío. En sus tiempos libres en el clandestinaje, o cuando estaba aquí en Cuba, se dedicó a investigar dos personalidades: la de Sandino y la de Darío porque él decía [...] que Darío era a lo cultural lo que Sandino era a lo político, que en Darío estaba nuestra identidad nacional. A Rubén Darío la burguesía lo mutiló, nos lo presentaron como un poeta que sólo le cantaba a los cisnes, a las doncellas, y Carlos Fonseca decía que esa imagen no era la de Darío, que era esa y era otra" (Cabezas, 1983: 122). 
El Frente Sandinista de Liberación Nacional construye el porvenir [...] que hace poco más de cincuenta años inició el indoamericano - obrero y campesino- Augusto César Sandino [... "El siglo que viene verá la mayor de las revoluciones que han ensangrentado la Tierra”, sentenció en 1892 nuestro Poeta Nacional Rubén Darío (Ortega, 1981: 31).

A efectos de la apropiación de Darío, se recorta una frase de un cuento construido a modo de monólogo que refiere las miserias del mundo. Se trata del cuento "¿Por qué?", publicado por primera vez en El Heraldo de Costa Rica, que representa uno de los escasos textos darianos en los que explícitamente se expone la cuestión social.

La figura de Darío había sido incorporada por el gobierno de Somoza García con el consenso de parte de la burguesía nicaragüense y de los sectores más conservadores. En ese marco, los intelectuales sandinistas, expresamente, pretenden arrebatarle a la burguesía y al régimen somocista la imagen del poeta, como señala el mismo Ramírez en 1982: "quitamos a Darío de las garras del enemigo" (Ramírez, 1982: 7). En otro texto de la misma época, "El profeta en su tierra", el novelista, cuya escritura, en ese periodo, estaba más centrada en el ensayo que en la narrativa, establece un paralelo entre Julio Cortázar y Rubén Darío. ${ }^{24}$ Ubica a ambos escritores en el mismo plano tanto en relación con la innovación literaria como con el compromiso político en la oposición al invasor estadounidense. Sobre el primer aspecto, apunta: "Rayuela, novela que es, a la narrativa hispanoamericana de hoy, lo que Cantos de vida y esperanza fue, por su valor innovador, novedoso y moderno, a la poesía hispanoamericana de entonces" (Ramírez, 1985b: 213-214). Sobre el segundo: "su 'Apocalipsis de Solentiname' [es] algo así como su canto a Nicaragua, igual que Darío había celebrado a la Argentina en su Canto a la Argentina. No una apoteosis del triunfo del progreso [...] aunque también [...] Rubén viera a 'tronos, suplicios, cadenas/ y con tiaras a tigres y hienas" (Ramírez, 1985b: 215-216). Luego establece el paralelismo entre Darío y Sandino:

Y en esa voz de poeta, sobre esos acentos, ¿no resonaría más tarde, no tan tarde, la de Sandino? Esa ocupación que denunciaba Darío en 1911 sería derrotada por Sandino en $1933[\ldots]$ armado con voz dariana de la "Oda a Roosevelt" cuando dice en su carta al presidente Hoover: "Yo estoy representando con mi ejército el propio sentir de mis conciudadanos [...] yo reconozco los recursos materiales de los que dispone su nación. Todo lo tienen, pero les falta una cosa: Dios (Ramírez, 1985b: 219).

${ }^{24}$ Ese texto es un discurso público, en oportunidad del reconocimiento de la Orden de la Independencia Cultural Rubén Darío, por parte del gobierno sandinista, a Julio Cortázar en su última visita a Nicaragua. Fue publicado en la edición homenaje a Julio Cortázar de Casa de las Américas, números 145-146 (julio-octubre 1984), 96-101, con el título "Darío y Cortázar". Aquí citamos por la versión publicada en Balcanes y volcanes y otros ensayos y trabajos (Ramírez, 1985b). 


\section{Diana Moro}

$\mathrm{Al}$ leer, en la carta de Sandino dirigida al presidente Hoover, ecos del poema "A Roosevelt", vincula las dos figuras que, para ese presente revolucionario, pretenden ser aglutinantes simbólicos. Define a Darío como un "profeta", un "visionario", porque fue capaz de anticipar que la Doctrina Monroe no significaba América para los americanos, sino América para los yanquis, y opone su lectura a la que había consolidado la burguesía "con la levita manchada por los excrementos de la intervención yanqui" (Ramírez, 1985b: 220). Desde esa nueva imagen, la Revolución lo rescata "no del olvido, sino de la superchería porque Darío siempre estuvo en el alma popular" (Ramírez, 1985b: 221), dice. Al presentar esa imagen de Darío construida por la burguesía, retoma la idea planteada ya en "Balcanes y volcanes": "una burguesía atrasada y atrofiada, impedida de entender a la nación y hacerse cargo de la nación” (Ramírez, 1985b: 221).

La inclusión de Darío en el repertorio antiimperialista no contradice la perspectiva planteada por los vanguardistas respecto del "mestizaje" cultural y del poeta como un paradigma de esa configuración.

Durante ese periodo, la imagen de Darío "mestizo" se refuerza y se actualiza. En la edición número 24 de El Pez y la Serpiente, correspondiente al verano de 1981, Pablo Antonio Cuadra escribe un artículo titulado "Notas sobre el desarrollo de una literatura asediada". ${ }^{25}$ Allí, plantea la tesis de una literatura construida con dos componentes, con los cuales se explicarían algunas innovaciones en la lengua dariana:

La literatura nicaragüense [...] comienza como una traducción; si se la mira desde el punto de vista del siglo xix, la mayoría del pueblo nicaragüense hablaba una lengua o jerigonza mezclada de palabras nahuas, chorotegas y castellanas. Había que hablar de un acto de traducir - que es tanto como traicionar - el pensamiento; para ir luego poco a poco posesionándose de la nueva lengua, descubriéndola, adivinándola, luchando doblemente con ella hasta lograr que la expresión (que es siempre una ex prisionera) se viera libre de sus dos cárceles, la propia del concepto y la ajena del léxico extranjero [...] Esta fue otra calistenia importante para el escritor y el poeta. Nosotros hemos encontrado, por ejemplo, que algunas de las innovaciones poéticas de Darío, son geniales utilizaciones de su náhuat oculto, es decir, de la sintaxis náhuatl con que todavía el pueblo construye, en ciertas regiones nicaragüenses, su español (Cuadra, 1997: 774).

Esa explicación de la poética dariana deudora del mestizaje, que es complementaria de la idea de dualidad planteada por Guadra en la década de 1960, y de la confluencia de dos fuerzas oceánicas y continentales, esbozada en ese texto temprano, escrito con motivo de su ingreso a la Academia Nicaragüense de la Lengua, convive con la figura "antiimperialista" de Darío que aún sigue vigente. ${ }^{26}$

${ }^{25}$ Ese artículo fue publicado posteriormente en Lectura crítica de la literatura americana (Cuadra, 1997).

${ }^{26}$ Jorge Eduardo Arellano, en 2016, publica un artículo titulado "Rubén Darío ante los Estados Unidos". Allí, concluye que "la visión rubendariana sobre los Estados Unidos se ma- 
Y para terminar el recorrido, aunque sin pretensiones de exhaustividad, resulta interesante aportar la visión que, en torno al mestizaje, expone Ramírez en un libro posterior, Tambor olvidado, publicado en 2007. El autor amplía la configuración del mestizaje con "el tercer componente clave, el africano" (Ramírez, 2007: 9). Si bien hay un tono de acusación al señalar que "de eso no se habla" y que "la herencia africana haya estado siempre bajo represión, y pasara a convertirse en un mudo estigma" (Ramírez, 2007: 12), no discute la tesis elaborada por Pablo Antonio Cuadra, sino que la asume como el punto de partida. En ese marco, ubica a Darío: "Si el Güegüence ha sido señalado como el representante del doble mestizaje hispano e indígena en la época colonial, Rubén Darío asume esa representación a partir de la época republicana, el fruto más preciado entre el mundo europeo y el mundo indígena, el mestizo indohispano por antonomasia" (Ramírez, 2007: 15).

Ramírez cita un fragmento de El nicaragüense y otro de Aventura literaria del mestizaje de Cuadra y cuestiona la segregación de la costa atlántica o caribe que implica el esquema identitario trazado por el vanguardista. Sin embargo, sostiene que Darío es fruto del triple mestizaje, aunque el tercer componente se halle en el silencio: "Rubén Darío se reconoce él mismo, efectivamente, como un mestizo fruto de los dos grandes ríos, uno indígena, otro español [...] Pero también es fruto de la cultura del silencio, que niega el cauce al tercer río que viene a dar a las aguas revueltas del gran mestizaje triple" (Ramírez, 2007: 19). Y toma distancia, claro, de la tesis de la superioridad de las razas; considera que esta "concepción etnocentrista" (Ramírez, 2007: 21) permitió justificar la empresa del colonialismo del siglo Xix. Señala el rechazo en algunos textos de Darío del concepto de "mulatez", lejos del ensalzamiento de "hispanidad" o "indianidad" (Ramírez, 2007: 24).

En gran medida, la perspectiva enfocada en la "modernidad" de la región centroamericana deudora del vínculo con Europa, desarrollada en "Balcanes y volcanes", que, evidentemente, se integraba en una formación discursiva de la época - décadas de 1960 y 1970 - , se sirve de la figura de Rubén Darío en virtud de su identificación con lo que el mismo Darío llamaba "la aristocracia del pensamiento", idea que implica la superioridad de cierto tipo de cultura y la posición subalterna de otras. En la primera década del siglo XxI, nuevamente, Ramírez vuelve a Darío ahora para sostener la tesis del mestizaje triple.

nifestó en dos direcciones. Una orientada hacia la crítica del expansionismo y de la política exterior de la superpoderosa nación; la otra hacia el reconocimiento de sus expresiones culturales" (Arellano, 2016: 24). 


\section{Conclusiones}

La lectura que compartimos de algunos ensayos sobre la figura de Rubén Darío - escritos por intelectuales a lo largo del siglo xx e inicios del xxI - evidencia la constitución histórica del sistema literario hegemónico nicaragüense. También muestra las múltiples intersecciones que lo conforman, con la figura de Darío como centro, convertida en una especie de emblema aglutinante. Éstas constituyen características salientes de un sistema literario considerado nacional, pero que ha concitado prestigio en la zona del Pacífico, la parte occidental y la zona centro de Nicaragua, las cuales ocupan la cuarta parte del total del territorio del país, con una mayoría de población blanca y ladina o mestiza indo-hispana, católica e hispanohablante. Incluso, en esa misma zona, todavía hoy, reclaman sus derechos y reivindican su especificidad étnica y cultural diversas comunidades y, más aún, los pobladores de la zona caribe o atlántica, área que abarca aproximadamente el cincuenta por ciento del territorio. En ese contexto, entonces, el sistema literario descrito es uno hegemónico, por tal motivo, hablamos de polisistemas, ya que obviar la existencia, por desconocidos, de otros sistemas lingüísticos culturales implicaría cerrar las posibilidades de indagación.

En el canon de ese sistema literario prestigioso, la obra de Darío ha ocupado un lugar indiscutido, aunque ha sido leída desde diferentes enfoques y, en consecuencia, han hecho hincapié o, aun, se han apropiado de uno u otro repertorio dariano específico. Además, la figura de Darío ha sido el foco de los debates sobre la literatura que han rebasado ampliamente el campo literario.

Por un lado, podemos concluir que la construcción discursiva de dos de los referentes más importantes del Movimiento Nicaragüense de Vanguardia, Pablo Antonio Cuadra y José Coronel Urtecho - quienes recuperan a Darío luego del distanciamiento vanguardista - ubica a Darío en el pivote de las elaboraciones sobre la cultura y la identidad nacional. El "ser nicaragüense", para ellos, consiste en una suerte de mestizaje indo-español, aunque con un valor puesto en el componente colonizador, en tanto propiciador de la modernidad por ser portador de la escritura. En este sentido, Darío representa una especie de paradigma de ese ser nacional "fruto de la confluencia de dos océanos", o bien, un colaborador de tal esencia. El grupo de la revista Ventana, liderado por Sergio Ramírez, recupera a Darío en términos vernáculos y sale a buscar al mundo, a través de las traducciones, estéticas diversas. Aunque también, al finalizar el periodo de vigencia del proyecto editorial, el mismo Ramírez sostiene que Darío es el soporte de los jóvenes poetas y escritores nicaragüenses y usa el adjetivo "perpetuo" para calificar su legado. También este grupo de jóvenes, en los años sesenta, sustentan su concepción de literatura en la tradición escrituraria. Así, los elementos vernáculos no alcanzan y requieren de redes trasatlánticas - aunque, 
en Nicaragua, la mirada hacia Europa se realiza desde el Pacífico - para dotar(se) de múltiples estéticas y proyectos literarios diversos.

Por otro lado, en cuanto a los repertorios darianos, se han retomado o reconstruido particularmente dos, durante el siglo xx y hasta nuestros días, que no se oponen, pero que son diferentes. Uno se compone de la mirada antiimperialista, la posibilidad de leer en Darío la construcción de un enemigo presente en el periodo vanguardista: recordemos la invasión norteamericana en 1912 y durante la década de 1980, la agresión permanente a través del financiamiento de la "Contra" por parte de la CIA. Los intelectuales pertenecientes al Frente Sandinista en el gobierno realizaron una apropiación de ese repertorio, incluso antes de la toma del poder. Otra construcción es la de la "nación mestiza", elaborada por Cuadra, por Coronel Urtecho en algunos textos y, hacia el primer decenio del siglo XxI, por Sergio Ramírez, quien plantea la tesis del mestizaje con triple componente. En esas argumentaciones, la figura de Rubén Darío aparece como centro. Los dos conjuntos de dichos repertorios, en los distintos discursos que hemos referido, son utilizados para explicar lo nacional nicaragüense, desde una perspectiva hegemónica, desde ciertos lugares de poder en el campo literario y político-cultural. Para ello, la literatura constituye un anclaje material de gran importancia.

\section{Bibliografía}

Arellano, Jorge Eduardo

"Rubén Darío ante los Estados Unidos", en Revista de la Academia de Geografia e Historia de Nicaragua, segunda época, tomo 78 (febrero 2016), 11-26.

Ayerdis García, Miguel

"La fiesta nacional dariana de 1941 o la canonización de la cultura oficial", en Istmo. Revista Virtual de Estudios Literarios y Culturales Centroamericanos, número 10 (enero-junio de 2005). Consultado en: https://istmo.denison.edu/n10/articulos/fiesta.html [15/04/2020].

BLANDÓN, Erick

"Rubén Darío: mutilación y monumentalización", en Jeffrey Browitt y Werner Mackenbach (editores). Rubén Dario. Cosmopolita arraigado. Managua: Instituto de Historia de Nicaragua y Centroamérica, 2010, 104-126.

"Presencia de Rubén Darío en los discursos del mestizaje", en Chasqui, volumen 40, número 2 (noviembre 2011), 171-183. Consultado en: https://jstor.org/stable/41342252seq=1 [08/02/2020].

Cabezas, Omar

"Entrevista", en Casa de las Américas, número 138 (mayo-junio 1983), 121-125. 


\section{Diana Moro}

\section{Cardenal, Ernesto}

"Introducción", en foaquín Pasos. Poemas de un joven. Managua: Nueva Nicaragua, 1987, 8-22.

Coronel Urtecho, José

Reflexiones sobre la historia de Nicaragua (de Gainza a Somoza): alrededor de la independencia. León, Hospicio, 1962.

"Introducción al tema de la universalidad nicaragüense", en Revista Conservadora, volumen 14, número 69 (1966), 2-7.

"Prólogo", en Leonel Rugama. La tierra es un satélite de la luna. Buenos Aires: Nueva América, 1987.

Cuadra, Pablo Antonio

"Rubén y la dualidad”, en El nicaragüense. San José: Libro Libre, 1987a, 17-24.

“Un nicaragüense llamado Rubén Darío", en El nicaragüense. San José: Libro Libre, 1987b, 70-77.

"Notas sobre el desarrollo de una literatura asediada", en Saúl Sosnowski. Lectura crítica de la literatura americana. Caracas: Biblioteca Ayacucho, 1997, 772-780.

"Introducción al pensamiento vivo de Rubén Darío", en Crítica Literaria II. Managua: Colección Cultural de Centroamérica, 2004, 107-129.

"La revolución hispanoamericana de Darío", en Rubén Darío. Del símbolo a la realidad. Obra selecta. Madrid: Real Academia Española y Asociación de Academias de la Lengua Española, 2016, 281-287.

Darío, Rubén

Poesía. Caracas: Biblioteca Ayacucho, 1977.

Even-ZoHAR, Itamar

“Teoría de los polisistemas", en Poetics Today, volumen 11, número 1 (primavera 1990), 9-26. Traducción de Ricardo Bermúdez Otero.

FERNÁNDEZ, Ramón

Colección de poetas españoles: Rimas de Fernando de Herrera. Madrid: Imprenta Real, 1786.

Gianni, Silvia

"Viajar, perder países... El desafío de cruzar las múltiples fronteras culturales que componen el panorama literario nicaragüense", en Revista Ístmica, número 11 (2007), 59-75.

Gramuglio, María Teresa

"Interrelaciones entre literatura argentina y literaturas extranjeras. Debates actuales e hipótesis de trabajo", en El Hilo de la Fábula, números 8-9 (2009), 16-23. 
HenríQuez, Gloriantonia

"El discurso cultural en la revista El Pez y la Serpiente, en sus primeros quince años (19611976)", en América: Cahiers du CRICCAL, números 9-10 (1992), 119-124.

MEdina, Julia

"Modernismo nómada y últimas gestas de Rubén Darío", en Carolina Bartalini y Rodrigo Javier Caresani (compiladores). Actas Congreso Internacional Rubén Darío: la sutura de los mundos. Buenos Aires: Universidad Nacional de Tres de Febrero, 2018, 485-493.

Morales, Arqueles

"Sergio Ramírez: gobernar con el mismo esmero con que escribo" (entrevista), en Casa de las Américas, número 151 (julio-agosto 1985), 70-74.

Moro, Diana

Sergio Ramírez, Rubén Darío y la literatura nicaragüense. Raleigh: A Contracorriente, 2015.

"La construcción somocista de la figura de Rubén Darío", en Anales de Literatura Hispanoamericana, número 46 (2017), 183-199.

"Nicaragua y una ventana al mundo. La revista Ventana (1960-1963)", en Revista Ístmica, número 23 (enero-junio 2019), 43-52.

Ortega, Humberto

"Discurso al Segundo Congreso del Partido Comunista de Cuba", en Casa de las Américas, número 125 (marzo-abril 1981), 31-33.

Ortega, Julio

"Post-teoría y estudios transatlánticos", en Iberoamericana, nueva época, año 3, número 9 (marzo de 2003), 109-117. Consultado en: https://www.jstor.org/stable/41673126? seq=1 $[13 / 02 / 2020]$.

"Trayecto transatlántico", en Anclajes, volumen 19, número 2 (diciembre 2015), 41-47. Consultado en: https://cerac.unlpam.edu.ar/index.php/anclajes/article/view/1006 $[22 / 01 / 2020]$.

RAMírez, Sergio

"Discurso en la constitución del jurado del primer premio literario Casa de las Américas 1982", en Casa de las Américas, número 131 (abril 1982), 3-9.

"Balcanes y volcanes", en Balcanes y volcanes y otros ensayos y trabajos. Buenos Aires: Nueva América, 1985a, 17-117.

"El profeta en su tierra", en Balcanes y volcanes y otros ensayos y trabajos. Buenos Aires: Nueva América, 1985b, 213-226.

Tambor olvidado. San José de Costa Rica: Aguilar, 2007. 


\section{Diana Moro}

\section{Schmigalle, Günther}

"Más apreciaciones sobre la imagen de España de Rubén Darío", en Anales de Literatura Hispanoamericana, volumen 32 (2003), 153-163.

\section{Solís, Pedro Xavier}

El movimiento de vanguardia en Nicaragua. Análisis y antología. Managua: Fundación Vida, 2001.

\section{Trigo, Abril}

"Los estudios transatlánticos y la geopolítica del neo-hispanismo", en Cuadernos de Literatura, número 31 (enero-junio 2012), 16-45.

Ventana. Publicación de Arte y Letras de los Estudiantes de la Universidad Nacional Autónoma de Nicaragua Edición facsimilar, preparada por Sergio Ramírez. Managua: Nueva Nicaragua, 1990.

WeLLinga, Klaas

Nueva cultura nicaragüense (debate sobre el realismo). Buenos Aires: Libros de Utopías del Sur, 1989.

Entre la poesía y la pared. Política cultural sandinista 1979-1990. Ámsterdam, San José: Thela Publishers/Flacso, 1994. 